\author{
Military Technical College \\ Kobry Elkobbah, Cairo, \\ Egypt.
}

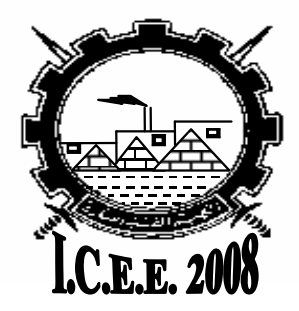

$4^{\text {th }}$ International Conference On Chemical \& Environmental Engineering 27-29 May 2008

\title{
THE EFFECT OF METALLIC ADDITIVES ON THE THERMAL DECOMPOSITION OF COMPOSITION B
}

\author{
EI-BASUONY* S. A. and MOSTAFA*H. E.
}

\begin{abstract}
Comp B, which is an explosive mixture of RDX and TNT, is used as the destructive charge in artillery shells, rockets and landmines. Previous work was done to improve Composition B performance by adding metallic additives in $12 \%$ by weight. In this paper Composition B mixtures with Aluminum and Magnesium were prepared and their effect on its thermal stability was studied by using a well known thermal analysis technique; Differential Scanning Calorimetry (DSC). Through heating the prepared samples from room temperature to $300^{\circ} \mathrm{C}$, with three different heating rates $(2,5$ and $10{ }^{\circ} \mathrm{C} / \mathrm{min}$ ). The data generated from DSC curves were employed in Kissinger kinetic method to calculate the needed activation energy for the thermal decomposition of the prepared samples. The obtained results show that the metallic additives have a negative impact on the thermal stability of the Composition B.
\end{abstract}

\section{KEYWORDS}

Thermal decomposition; Differential Scanning Calorimetry; Composition B.

\footnotetext{
* Egyptian Armed Forces
} 


\section{INTRODUCTION}

Composition B (Comp B) is an explosive mixture composed of RDX (1,3,5-trinitro 1,3,5-triazacyclohexane) and TNT (2,4,6-trinitro toluene), with (60/40) ratio by weight respectively. It is used as the destructive charge in artillery shells, rockets and landmines.

The energy of high explosives can be increased by raising the contribution of the heat of explosion " $Q_{v}$ ", [1]. In purely organic explosives, it is evident that the available heat of explosion " $Q_{v}$ " is limited by the heats of combustion of the constituent fuel elements (carbon and hydrogen).

A simple way to increase the value of " $Q v$ " is by adding to the explosive an elemental fuel which has a high heat of combustion. Several metal fuels - e.g. Beryllium, Boron, Lithium, Aluminum, Magnesium and Zinc - can be used with high explosives in order to increase their heat of explosion and performance [2]. Aluminum and Magnesium are the most common fuel additive due to their availability, non-toxicity, ease of burn and low-cost. A previous study showed that adding $12 \%$ Aluminum (by weight) to the explosive Comp $B$ is the optimum ratio for enhancing its explosive properties [3].

Generally, all explosives evolve heat during decomposition [4]. Though the chemical decomposition is slow, the reaction rate increases in time and can spontaneously reach, due to thermal and autocatalytic effects, a stage where the slow chemical decomposition changes into burning or even catastrophic detonation. This evolved heat could be traced through the acceleration of the decomposition process with quick, safe and reliable lab-scale tests; such as thermal analysis techniques. A typical thermal analysis technique is the Differential scanning calorimetry (DSC). The differences in heat flow into a sample and a reference are measured as a function of sample temperature while the two are subjected to a controlled temperature program. Such technique enables the monitoring of some processes e.g. specific heat capacity change, melting, vaporization, sublimation and decomposition reactions.

In this paper, micron-sized Aluminum and Magnesium were added (in $12 \%$ by weight) to Comp B, and their effects on the thermal behavior of Comp B were studied using DSC technique. The observed results and the data generated during this work are discussed.

\section{EXPERIMENTAL}

\section{Preparation of the Samples}

Comp B was heated up to $90^{\circ} \mathrm{C}$, in a water path, and maintained at that temperature for 30 minutes until complete melting. After melting of comp B, Aluminum of particle size $15 \mu \mathrm{m}$ was added gradually during stirring to the melting comp B. Stirring was continued for another 30 minutes after the complete addition of Aluminum, to prevent its settling to ensure the homogeneity of the mixture. The same process was applied for Magnesium of particle size $30 \mu \mathrm{m}$. 


\section{Thermal Analysis Experiments using DSC Technique}

Thermal characterization of energetic materials is essential for recognizing their stability and safety. In this respect, the characterization activities are focused on using thermal analysis techniques such as Differential Scanning Calorimetry (DSC). Standard DSC technique usually applies a linear temperature increase, during which the sample may pass certain weight losses related to the evolution of gaseous decomposition products followed by melting/decomposition process of the investigated material. In this way, the physicochemical properties like melting point and decomposition temperature can be determined.

The samples were placed in sealed aluminum cups into Linseis DSC apparatus (Model: L63/45). They were heated from room temperature to $300^{\circ} \mathrm{C}$ [5] with three different heating rates $\left(2,5\right.$ and $\left.10^{\circ} \mathrm{C} / \mathrm{min}\right)$ [6-7] in atmosphere of static air. The results were interpreted using Linseis evaluation code [8].

\section{RESULTS AND DISCUSSION}

\section{DSC Results}

DSC curves of explosive Comp B-Based compositions are shown in Fig. 1 to 3 . These curves show a sharp endothermic peak around $80^{\circ} \mathrm{C}$ and the next DSC event is the decomposition as a broad exothermic peak around $229^{\circ} \mathrm{C}$. The enthalpy and temperature of these peaks are shown in Table 1.

Table 1 the enthalpy and temperatures of DSC for Comp B-Based compositions

\begin{tabular}{|l|c|c|c|c|}
\hline \multirow{2}{*}{} & \multicolumn{2}{|c|}{ Endothermic peak } & \multicolumn{2}{c|}{ Exothermic peak } \\
\cline { 2 - 5 } & Temp. & Enthalpy & Temp. & Enthalpy \\
\cline { 2 - 5 } & $\left({ }^{\circ} \mathrm{C}\right)$ & $(\mathrm{J} / \mathrm{g})$ & $\left({ }^{\circ} \mathrm{C}\right)$ & $(\mathrm{J} / \mathrm{g})$ \\
\hline Comp B-R10* & 82.1 & 37.64 & 239.8 & -4254.77 \\
Comp B-AI-R10 & 82.1 & 16.16 & 239.6 & -1985.73 \\
Comp B-Mg-R10 & 82.3 & 28.85 & 237.4 & -2456.97 \\
\hline Comp B-R5 & 80.7 & 41.78 & 229.3 & -3040.13 \\
Comp B-AI-R5 & 81.0 & 43.56 & 229.8 & -3254.75 \\
Comp B-Mg-R5 & 80.8 & 30.61 & 232.7 & -2595.78 \\
\hline Comp B-R2 & 79.8 & 44.95 & 221.4 & -2518.34 \\
Comp B-AI-R2 & 80.0 & 50.90 & 218.4 & -3617.14 \\
Comp B-Mg-R2 & 79.8 & 33.84 & 217.4 & -2622.75 \\
\hline
\end{tabular}

${ }^{*} \mathrm{R} 10=$ experiment performed at heating rate $10^{\circ} \mathrm{C} / \mathrm{min}$

The endothermic heat of fusion of comp $B$ at $10^{\circ} \mathrm{C} / \mathrm{min}$ heating rate was $37 \mathrm{~J} / \mathrm{g}$ and the decomposition exothermic peak for comp B was $239^{\circ} \mathrm{C}$ which agree with the results reported by Lee and Hsu [10]. The observed endothermic peak corresponds to the melting of TNT.[10-11]. However, the exothermic peak is a more complicated one since the melting point of $\mathrm{RDX}$ is $203-205^{\circ} \mathrm{C}$ and decomposes at $215^{\circ} \mathrm{C}$ [11] and the ignition temperature of Comp B is $226-239^{\circ} \mathrm{C}$ [3]. 
The influence of the experiments heating rate on the shape of DSC curves is clearly visible from figs. 4 and 5 , as decreasing the heating rate shifted the thermal events to the low temperature side [11-12].

\section{Determination of the Activation Energy by Kissinger Method}

The activation energy can be determined, using Kissinger's equation [9] shown below, from the correlation between peak temperature and heating rate for several thermal analysis curves. This method is based on the equation

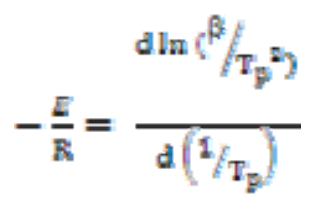

Where:
$\mathrm{E}$ : activation energy
$\mathrm{R}$ : universal gas constant
$\beta$ : heating rate
Tp : peak temperature of the DSC scan at that rate
$(8.314 \mathrm{~J} / \mathrm{mol} \mathrm{K})$
$(\mathrm{J} / \mathrm{mol})$
$(\mathrm{K} / \mathrm{min})$
(K)

When $\ln \left(\beta / \mathrm{T}_{\mathrm{p}}{ }^{2}\right)$ is plotted against $\left(1 / \mathrm{T}_{\mathrm{p}}\right)$ a straight line is obtained, and the activation energy is calculated from the slope $-E / R$.

Data generated from DSC experiments were used to calculate the activation energies of decomposition for explosive Comp B-based compositions by using Kissinger kinetic method. The activation energy of decomposition step for Comp B was $174 \mathrm{~kJ} / \mathrm{mol}$ [10], the addition of Aluminum and Magnesium has reduced the activation energy by 13 and 15\% respectively. The results are shown in table 2 .

Table 2. The activation energy of decomposition for explosive Comp B-based compositions

\begin{tabular}{|l|c|}
\hline Composition & $\begin{array}{c}\text { Exothermic peak } \\
\text { activation energy }(\mathrm{J} / \mathrm{mol})\end{array}$ \\
\hline Comp B & 174020.3 \\
\hline Comp B/Al & 150857.5 \\
\hline Comp B/Mg & 147939.3 \\
\hline
\end{tabular}

\section{CONCLUSIONS}

Since explosives readily endanger personal safety, it is important to estimate the risks that they pose. DSC is a safe and simple technique for studying its stability.

In this paper, micron-sized metal additives (Aluminum and Magnesium) were added (in $12 \%$ by weight) to Comp $B$ in order to enhance its performance, and their effects on the thermal behavior of Comp B were studied using Differential scanning Calorimetry (DSC). The observed results and the data generated during this work 
showed that the addition of Aluminum and Magnesium has reduced the activation energy of the thermal decomposition of Comp B by a ratio of 13 and $15 \%$ respectively. This means that the enhanced compositions are less stable and more subtle to premature explosions than the original substance. However, this controversy could be handled through storing these enhanced compositions with utmost precautions to preserve the gained increase in performance without affecting its safety.

\section{REFERENCES}

[1] S. Nicolich, J. Niles, D. Doll, M. Ray, M. Gunger, A. Spencer, "Development of a Novel High Fragmentation/High Blast Melt Pour Explosive", Proceedings IM\&EM Symposium, Orlando, USA, (2003).

[2] E.L. Drezen; "Phase Changes in Metal Combustion", Progress in Energy and Combustion Science, Vol.26, pp. 57-78, USA, (2000).

[3] M.H.Hasan; "Study of the Explosive Characteristics of Energized High Explosives", M. Sc. thesis, MTC, Cairo, Egypt, (2005).

[4] B. Roduit, Ch. Borgeat, B. Berger, P. Folly, J.N. Aebischer, H. Fierz and F. Stoesel, "Advanced Tools for Thermal Aging and Safety Analysis", Linseis Thermal Analysis Bulletin, July 2005.

[5] S. Zeman, "Thermogravimetric analysis of some nitramines, nitrosamines and nitroesters", Thermochimica Acta, Vol. 230, pp 191-206, (1993).

[6] W.P.C. de Kelrk, C. Popescu and A.E.D.M. van der Heijdn, "Study on the Decomposition Kinetics of FOX-7 and HNF", Journal of Thermal Analysis and Calorimetry, Vol. 72, pp 955-966, (2003).

[7] E.L.M. Krabbendam-LaHaye, W.P.C. de Klerk and R.E. Krämer, "The Kinetic Behaviour and Thermal Stability of Comercially Available Explosives", Journal of Thermal Analysis and Calorimetry, Vol. 80, pp 495-501, (2005).

[8] Linseis Data Evaluation for Windows, Ver. 3.00.

[9] H.E.Kissinger,, Analytical Chemistry, Vol.29(11), pp 1702-1706, (1957).

[10] J.S. Lee and C.K. Hsu, "The thermal behaviors and safety characteristics of composition B explosive", Thermochimica Acta, Vol.367-368,pp 371-374, (2001).

[11] T. Hatakeyama and Z. Liu, "Handbook of Thermal Analysis", pp 42, John Wiley \& Sons Ltd, (1998).

[12] R.A. Meyers, "Encylopedia of Analytical Chemistry", Vol.15, pp 13212, John Wiley \& Sons Ltd, (2000). 


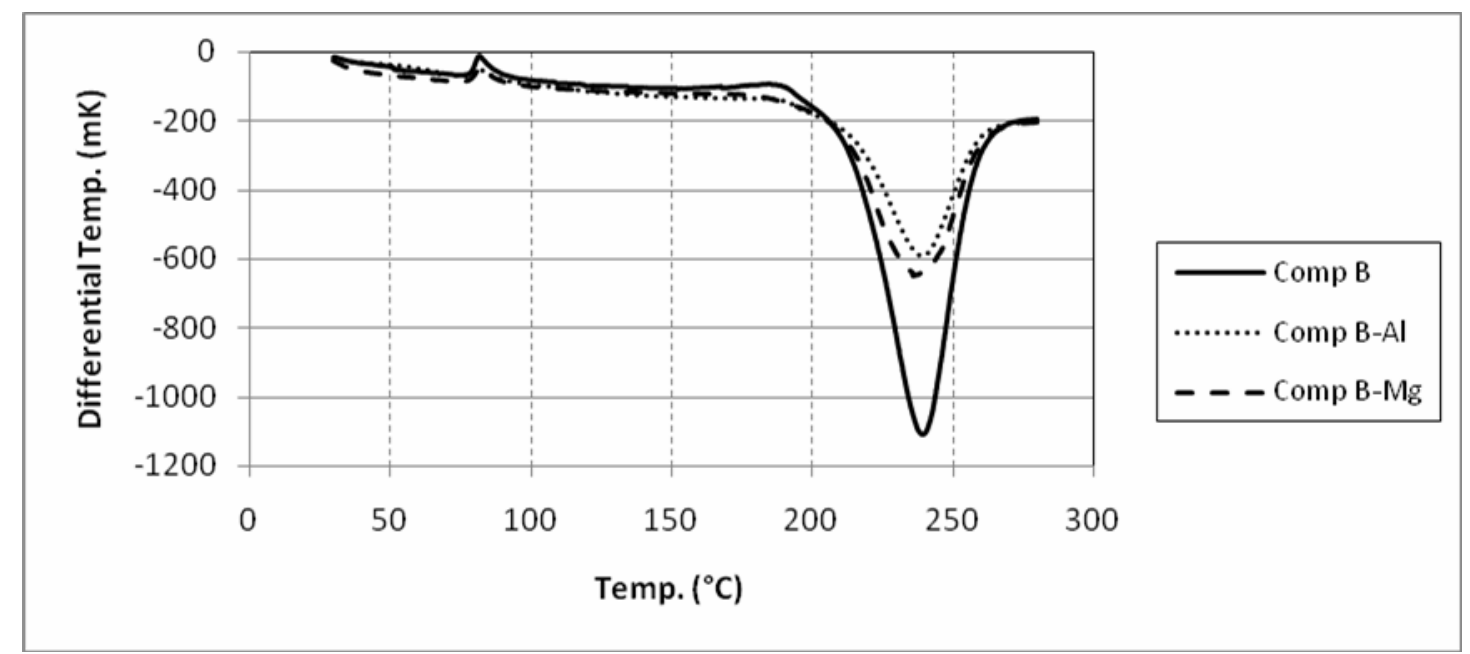

Fig.1 DSC curves at heating rate $\left(10^{\circ} \mathrm{C} / \mathrm{min}\right)$

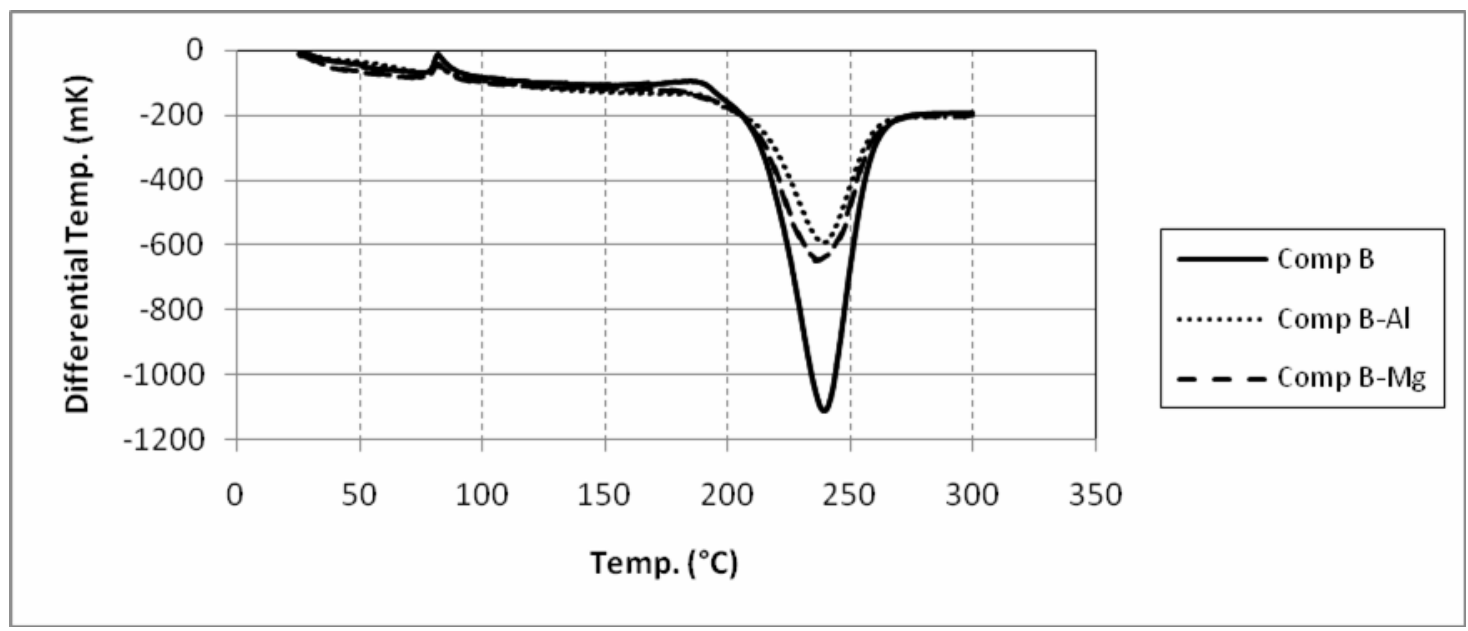

Fig. $2 \mathrm{DSC}$ curves at heating rate $\left(5^{\circ} \mathrm{C} / \mathrm{min}\right)$

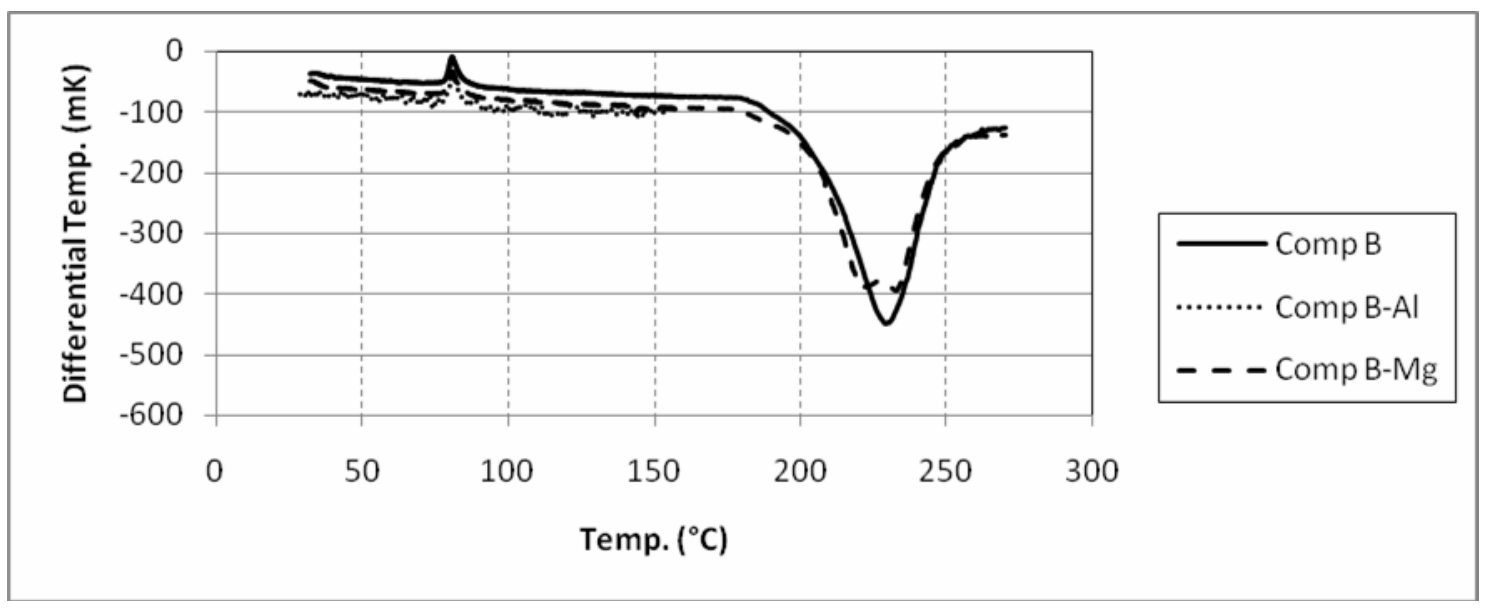

Fig. $3 \mathrm{DSC}$ curves at heating rate $\left(2^{\circ} \mathrm{C} / \mathrm{min}\right)$ 


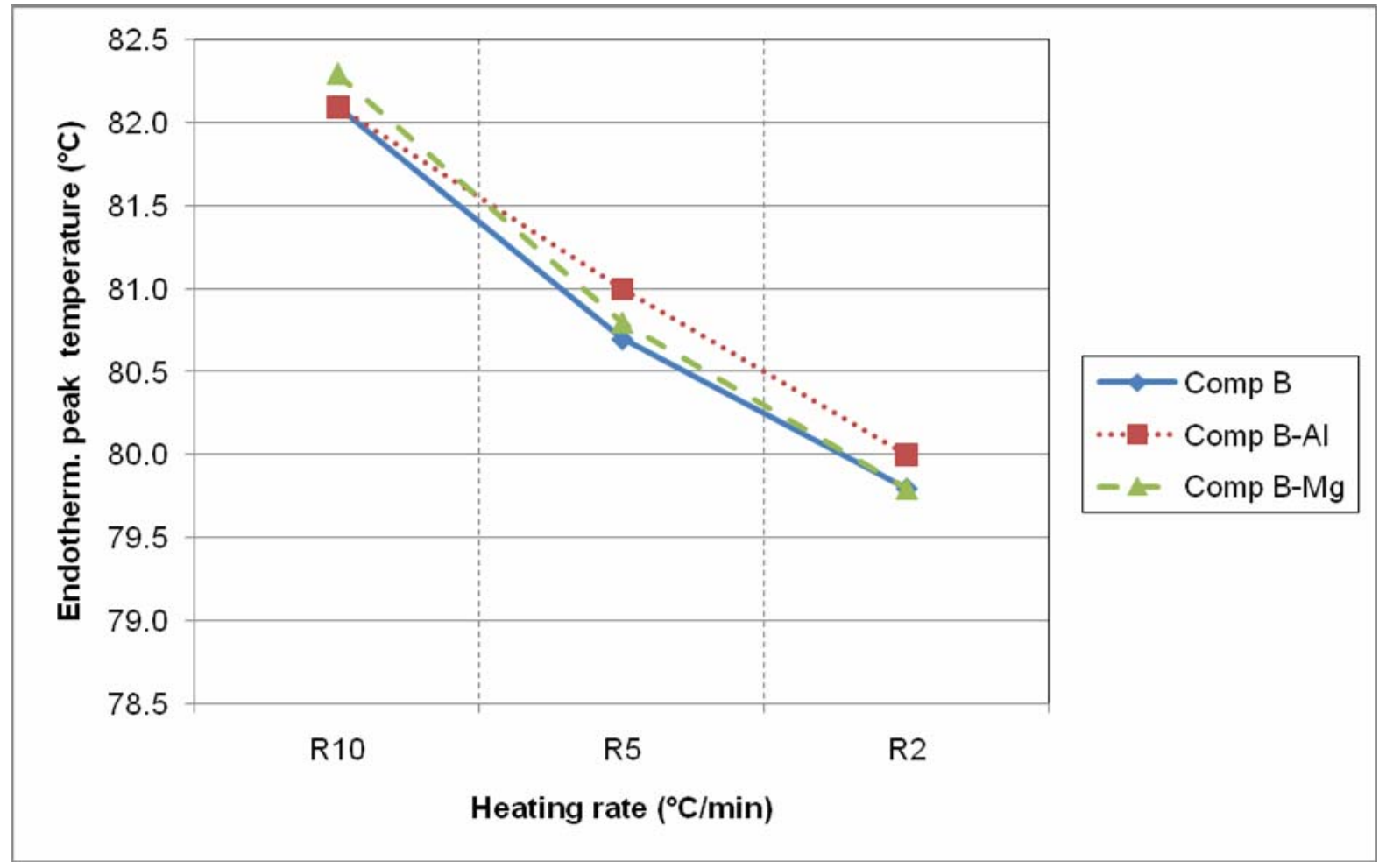

Fig.4 The effect of heating rate on the endothermic peak temperature

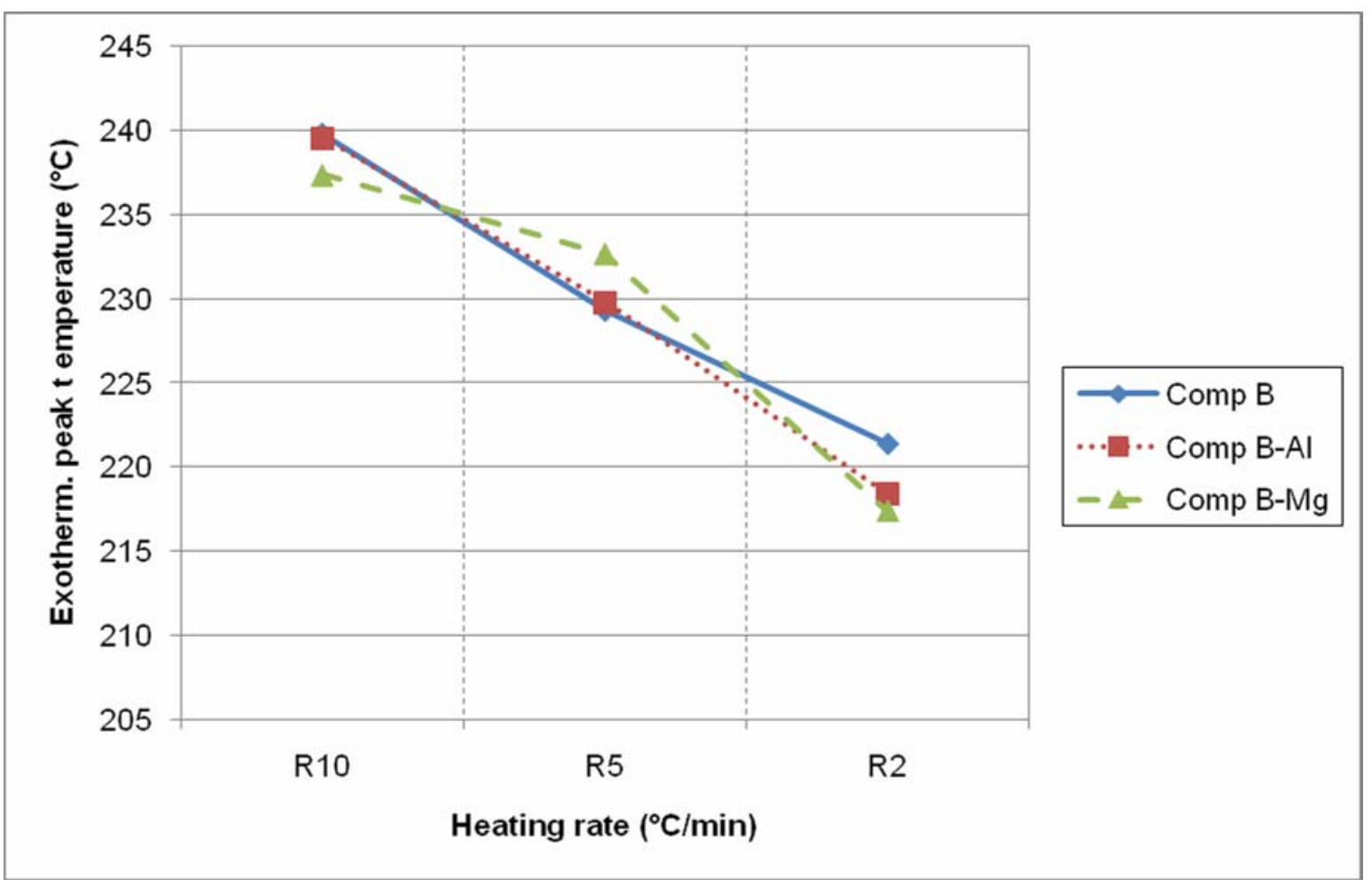

Fig.5 The effect of heating rate of the exothermic peak temperature 